\section{Die Akademie für Fort- und Weiterbildung in der Radiologie setzt seit April ein neues Evaluationssystem ein ... und warum Evaluation so wichtig ist!}

Seit über 10 Jahren bemüht sich die Akademie für Fort- und Weiterbildung in der Radiologie in besonderem Maße um die Qualität der Aus- und Weiterbildung der Radiologen. Die Qualität der Veranstaltungen, aufbauend auf der Befähigung der Referenten, hat für uns oberste Priorität. Die Ergebnisse einer gewissenhaft durchgeführten Evaluation sind deshalb bei der Nachlese und auch bei der Planung von Veranstaltungen von äußerster Wichtigkeit.

Um diese Qualitätsstandards noch zu verbessern, war es an der Zeit, einen in die Jahre gekommenen Fragebogen zu überarbeiten und ein neues Evaluationssystem einzusetzen, das die Möglichkeit der multimedialen Befragung zulässt, von beliebig vielen Standorten genutzt werden kann, Service-Schnittstellen integrierbar ist.

Seit April 2014 setzen wir in allen Veranstaltungen, die mit uns in Zusammenarbeit evaluiert werden, neue und auf wenige Fragen reduzierte, aber aussagekräftigere Fragebogen ein. Zum einen soll die Qualität der Referenten und der Themen beurteilt werden, zum anderen die Organisation der Veranstaltung. Der einzelne Veranstalter erhält sogar die Möglichkeit, individuelle Fragen zu stellen.

Sie, als Teilnehmer, haben die Möglichkeit, die Fragen direkt auf dem Bogen zu beantworten, mittels QR-Code über Mobile Devices oder über eine Internetadresse mit einem Zugangscode (TAN). Alle Angaben dazu finden Sie auf dem Fragebogen. stark im Berichtswesen und über Web-

In naher Zukunft wird es auch die Möglichkeit geben, Ihnen den Zugangslink für die Beantwortung der Fragen per E-Mail mitzuteilen.

Die Auswertungen können individuell und im Vergleich erstellt werden, an Veranstalter und Referenten per E-mail verschickt oder online über einen Link abgerufen werden. Sie geben wertvolle Hinweise für die weitere Planung und werden auch als Nachweis für die Erfahrung und Eignung der Referenten in diesem Bereich verwendet. Immer öfter hören wir, dass diese Berichte z. B. innerhalb von Bewerbungsverfahren nachgefragt werden.

Über die Auswertungen erfolgt auch die jährliche Verleihung des Wachsmannpreises. Dieser wird an die 5 bestbewerteten Referenten des Akademie-Programms verliehen und ist mit $500 €$ dotiert.

Evaluation kann die Professionalisierung der Lehre ebenso unterstützen wie die Verbesserung organisatorischer Prozesse und bringt so in vielerlei Hinsicht Nutzen für Sie als Veranstalter von Fortbildungen, für Sie als Referent und vor allem für Sie als Teilnehmer.

Außerdem zeigen die Ergebnisse der Evaluation Verbesserungsmöglichkeiten auf

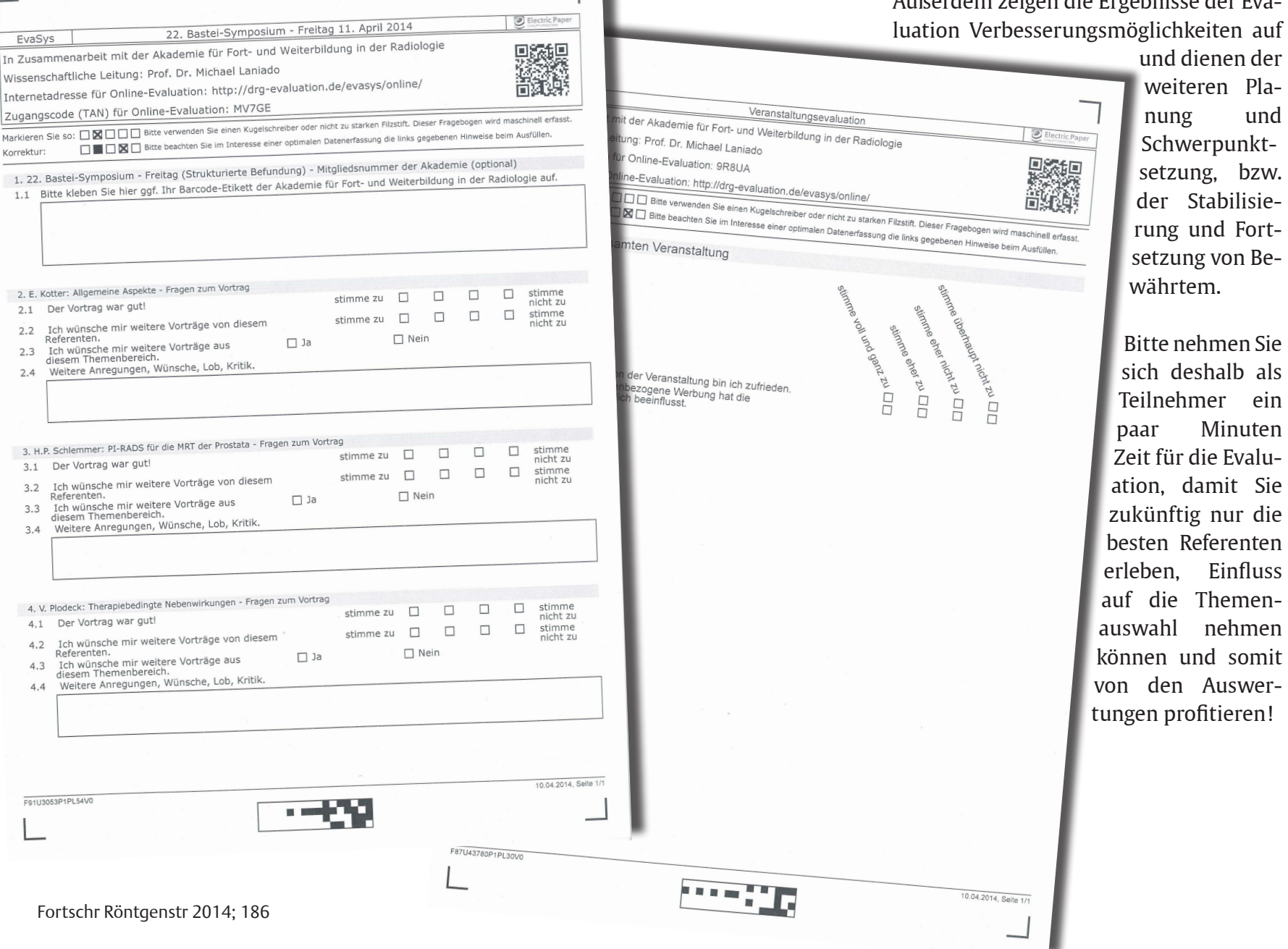

